\title{
Blueberry pomace, valorization of an industry by-product source of fibre with antioxidant capacity
}

\author{
Camila TAGLIANI ${ }^{1}$, Claudia PEREZ ${ }^{1}$, Ana CURUTCHET ${ }^{1}$, Patricia ARCIA ${ }^{1,2}$, Sonia COZZANO ${ }^{1 \star}$
}

\begin{abstract}
The industrial by-product of blueberry juice, a source of fibre with antioxidant capacity was used to develop cookies. Once dried and ground the blueberries by-product, its composition and functional properties were analyzed and used to develop fibre enriched cookies. A central composite design was used to optimize the cookie formulation maximizing antioxidant and total polyphenol content varying fibre content $(3-9 \mathrm{~g} / 100 \mathrm{~g})$, baking temperature $\left(160-180^{\circ} \mathrm{C}\right)$ and dough thickness $(0.5-1.0 \mathrm{~cm})$. Antioxidant capacity and total polyphenol content showed both a similar behaviour, increasing when fibre content increases. The increasing of dough thickness and baking temperature decreases the antioxidant capacity and total polyphenol content. Cookie with $9 \%$ fibre, $180{ }^{\circ} \mathrm{C}$ baking temperature and $0.50 \mathrm{~cm}$ dough thickness and cookie with $9 \%$ of fibre, $170^{\circ} \mathrm{C}$ baking temperature and $0.75 \mathrm{~cm}$ dough thickness showed maximum antioxidant capacity and polyphenol content with no significant differences between them; both cookies can be labelled using a fibre claim.
\end{abstract}

Keywords: antioxidant fibre; industry waste; blueberry pomace; response surface methodology; functional food.

Practical Application: Processing fruit into juice generates waste with its corresponding environmental impact. Blueberry by-product could be considered a bioactive-rich ingredient with a prolonged shelf-life, source of dietary fibre and phenols. The growing interest of consumers for eating healthy products has led the industry to improve the nutritional composition of food. This improvement may be achieved by adding functional ingredients, like blueberry pomace, to widely consumed food products.

\section{Introduction}

Industrial and agricultural waste of fruit and vegetable processing are an important source of bioactive compounds (Ignat, et al., 2011) which is the case of blueberry juice industry. The blueberry juice obtention generates waste that may be up to $20 \%$ of the initial fruit weight (Šarić et al., 2016).

Blueberries, apart from being rich in fibre, minerals and vitamins, are a relevant source of antioxidants, which have documented health promoting effects (Šarić et al., 2016). They have a particularly high content of polyphenols, anthocyanins, phenolic acids, flavanols, flavonols and tannins (Szajdek \& Borowska, 2008). Ignat et al. (2011) and Šarić et al. (2016) observed that one of the richest sources of phenolic compounds is the blueberry pomace with an important antioxidant capacity.

There is many literature over dietary fiber and antioxidants but these compounds are investigated independently as non-related compounds, may be for the differences in their chemical structures, physicochemical and biological properties, and metabolic pathways (Saura-Calixto, 2011).

Blueberry by-product can be processed, to obtain blueberry pomace powder. It could be used as ingredient with a prolonged shelf-life. This pomace combine the physiological effects of dietary fiber and antioxidants, in accordance with the concept "antioxidant dietary fiber", defined by Saura-Calixto (1998).

Potential uses of blueberry pomace powder include cookies and cereal-based products, among others. According to Vitali et al.
(2009), the most consumed and popular bakery products around the world are cookies for being low-cost, ready-to-eat product and involving a long shelf life. Consumers are turning to more health conscious. As a result, it can be seen an increasing need for healthy products that led to changes in the cookies' nutritional composition, which may be enhaced by adding functional ingredients, such as blueberry pomace.

In order to guarantee that the cookies supplemented with blueberry pomace are a source of fibre with antioxidant capacity, efforts should be directed to formulate the product, taking into account formulation and process. Although it may be reasonable thinking that a rise in fibre content produces an increase in antioxidant capacity in a direct way, this may be not at all. Bilgili et al. (2007) assayed the addition of different levels of fibre from apple in cookies and observed that an increase of fibre content decrease the antioxidant capacity. Food fortification with fibre rich in phenolic compounds can result in the loss of absorption of these antioxidants by trapping them within the fibre matrix and forming chemical complexes and colloidal structures that reduce their bioavailability (Palafox-Carlos et al., 2011). On the other hand, process conditions can affect functional properties. It is known that temperature has a negative effect on bioactive compounds, such as antioxidants and phenolics compounds that are thermolabile in nature. Ross et al. (2011) found that in grape pomace heating at temperatures above $180{ }^{\circ} \mathrm{C}$ causes a reduction in the antioxidant capacity. 
With focus in the development of a new product source of antioxidants and dietary fibre and revalorize the blueberry juice waste, the aim of this work was to optimize antioxidant capacity and polyphenol content in the formulation of cookies supplemented with blueberry pomace.

\section{Materials and methods}

\subsection{Blueberry pomace obtention}

Fresh blueberry pomace was obtained from juice processing by tangential microfiltration. The blueberries were O'Neill variety, from Uruguay. Blueberry pomace was dried in a convection oven at $45 \pm 2{ }^{\circ} \mathrm{C}$ until $13 \mathrm{~g} / 100 \mathrm{~g}$ moisture content. When pomace reached room temperature, was ground in a mill (Retsch ZM 200), the fraction that passed through the $1 \mathrm{~mm}$ sieve was used.

\subsection{Cookie formulation}

Blueberry cookies with 3,6,9\% fibre content were prepared. The following ingredients were used: water (20.0\%), blueberry pomace powder (fibre content, variable), wheat flour (variable), vegetable oil (17.5\%), milk powder (10.0\%), sucralose (Splenda ${ }^{\circledR}$, USA) $(2.3 \%)$, whey protein concentrate $80 \%$ Friesland Campina DMV (Netherlands)(1.9\%), baking powder (1.4\%), flavour vanilla powder (1.0\%), and powdered soy lecithin from Archer Daniels Midland Company ADM, (USA)(0.6\%). Content of wheat flour was adjusted according to final fibre expected in the cookie $(3,6,9 \%)$. Blueberry pomace fibre content was determined in the proximate composition.

Cookies' dough was made mixing ingredients after that was rolled out to disks of $4 \mathrm{~cm}$ of diameter and $0.50,0.75$ and $1.0 \mathrm{~cm}$ of height, and baked in a convection oven during twelve minutes. Temperatures varied between 160 and $180^{\circ} \mathrm{C}$, according to the experimental design.

\subsection{Experimental design}

Response surface methodology (RSM) was used to optimize the formulation of blueberry cookies to maximize functional properties. Experiments were carried out varying fibre content (blueberry pomace), baking temperature and dough thickness, according to a three-factor central composite design that comprised sixteen points: eight factorial, six axial, and two central points. Independent variables were tested at three different experimental levels $(-1,0,1)$ : fibre content percentage $(3,6,9 \%)$, baking temperature $\left(160,170,180^{\circ} \mathrm{C}\right)$ and dough thickness $(1.0,0.75,0.50 \mathrm{~cm})$ respectively. Antioxidant capacity determined by radical scavenging potency of ABTS assay and total polyphenol content (TPC) were the response variables.

\subsection{Proximate analyses}

Proximate composition was determinated on the blueberry pomace powder. Protein and Total Dietary Fibre (TDF) were calculated using AOAC methods, 984.13, 985.29 respectively (Association of Official Analytical Chemists, 2012). Fat was assayed following the ISO-6492-1999 (International Organization for Standardization, 1999). Moisture was determined by gravimetric analysis using a convection oven at $105^{\circ} \mathrm{C}$ until constant weight.
Ash was determined following ISO 5984-2002 (International Organization for Standardization, 2002). Total carbohydrates content was obtained by difference.

\subsection{Phenolic compounds}

\subsubsection{Extraction}

Phenolic compounds were performed on blueberry pomace powder and cookies. Extractable and hydrolysable phenolic compounds were extracted following Vitali et al. (2009). A mixture of $\mathrm{HCl}_{\text {conc }} /$ methanol/water $(1: 80: 10 \mathrm{v} / \mathrm{v})$ was used for the extractable fraction, like Gao et al. (2002). Briefly, $200 \mathrm{mg}$ of grinded sample were extracted with $4 \mathrm{~mL}$ of the $\mathrm{HCl}$-methanol solution for two hours at room temperature in a shaker. The mixture was afterwards centrifuged at $1358 \mathrm{~g}$ for 10 minutes on a centrifuge (Thermo Scientific, Sorvall ST-8R). Total phenolic compounds and antioxidant capacity were determinated in the recovered supernatant.

Hydrolysable compounds were extracted from the residues remaining from the first sample extraction, it were mixed with $22 \mathrm{~mL}$ of acidified methanol $\left(10: 1 \mathrm{v} / \mathrm{v}\right.$, methanol/ $\left.\mathrm{H}_{2} \mathrm{SO}_{4 \text { conc }}\right)$ following Hartzfeld et al. (2002). This mix was placed in a shaking water bath $\left(85^{\circ} \mathrm{C}, 20\right.$ hours). Antioxidant capacity and total phenolic compounds were determinated in the supernatants obtained after centrifugation (10 min, $3500 \mathrm{rpm}$ ).

\subsubsection{Total polyphenol content}

Folin-Ciocalteau method (Singleton \& Rossi, 1965) modified by Gao et al. (2002) was used to determinate Total Phenolic Content (TPC) of extracts. An aliquot of the samples $(0.2 \mathrm{~mL})$ was added to $1.5 \mathrm{~mL}$ of freshly diluted (1:10) Folin-Ciocalteau reagent. The mixture was left at rest for 5 minutes. After, $1.5 \mathrm{~mL}$ of $(60 \mathrm{~g} / \mathrm{L})$ sodium carbonate solution was added. The mixture was incubated for $90 \mathrm{~min}$. and the absorbance read at $725 \mathrm{~nm}$ in a Shimadzu 1800 UV-Visible spectrophotometer. Gallic acid was used as standard, results were expressed in milligrams of gallic acid per gram of sample.

\subsubsection{Total monomeric anthocyanins}

Anthocyanins were quantificated the $\mathrm{pH}$ differential method of Wrolstad (2001). Samples were diluted in pH 1.0 and pH 4.5 buffers, 1:50 (blueberry pomace) or 1:10 (blueberry cookies) and measured at 510 and $700 \mathrm{~nm}$ in a Shimadzu 1800 UV-Visible spectrophotometer. Results were expressed in $\mathrm{mg}$ of anthocyanins per $100 \mathrm{~g}$ of dry sample.

\subsubsection{Antioxidant capacity}

Antioxidant capacity was tested using the ABTS radical cation discoloration assay, following Re et al. (1999) with modifications.

ABTS stock solution was prepared diluting the reagent to a concentration of $2.5 \mathrm{mM} .2 .5 \mathrm{~mL}$ of this solution were mixed with $44 \mu \mathrm{L}$ of potassium persulfate $140 \mathrm{mM}$ and remained in the dark for 16 hours until the complete formation of ABTS radical cation. Trolox standard curve was made using Trolox in ethanol:water $(50: 50 \mathrm{v} / \mathrm{v})$, from 0 to $2.0 \mathrm{mM}$ final concentration. 
Ethanol:water (50:50) solution was used to dilute the ABTS stock solution to an absorbance of $0.7( \pm 0.02)$ at $734 \mathrm{~nm}$. Then, $3 \mathrm{~mL}$ of this solution were added to to $30 \mu \mathrm{L}$ of extract or Trolox standard solution, which were left standing during 30 minutes in the dark.

Absorbance was read in a Shimadzu 1800 UV-Visible spectrophotometer at $734 \mathrm{~nm}$.

\section{Statistical analysis}

All analyses were performed in triplicate, data reported as mean $\pm \mathrm{SD}$. One way analysis of variance (ANOVA) was performed on each assay, and differences between samples were determined with the Tukey test $(\alpha \leq 0.05)$. 2014).

Analyses were performed using InfoStat software (InfoStat,

In the optimization study, the results were analyzed using Response Surface Methodology (RSM) (Gacula, 1993). Both Antioxidant capacity and Polyphenol content, in related with independent variables (fibre content, baking temperature and dough thickness) were submitted to a multivariate regression analysis and fitted to a second-order model equation (Equation 1) provided in the design:

$$
\begin{aligned}
& Y=B_{0}+B_{1} X_{1}+B_{2} X_{2}+B_{3} X_{3}+B_{11} X_{1}{ }^{2}+B_{22} X_{2}{ }^{2}+ \\
& B_{33} X_{3}{ }^{2}+B_{12} X_{12}+B_{13} X_{13}+B_{23} X_{23}+\text { Error }
\end{aligned}
$$

where, $\mathrm{Y}$ is the dependent variable ( $\mathrm{Y} 1$ is the antioxidant capacity, $\mathrm{Y} 2$ is the polyphenol content), $\mathrm{B}_{0}$ is the intercept (constant), $\mathrm{B}_{1}, \mathrm{~B}_{2}, \mathrm{~B}_{3}$ the linear, $\mathrm{B}_{11}, \mathrm{~B}_{22}, \mathrm{~B}_{33}$ the quadratic and $\mathrm{B}_{12}, \mathrm{~B}_{13}, \mathrm{~B}_{23}$ the interaction effects, $\mathrm{X}_{1}, \mathrm{X}_{2}$ and $\mathrm{X}_{3}$ the independent variables: fibre content, baking temperature, dough thickness.

Software Statgraphics (Centurion XVI Version 16.1.03, Virginia, USA) was used.

\section{Results and Discussion}

\subsection{Proximate composition and functional properties of blueberry pomace powder}

Blueberry pomace powder proximate composition is presented in Table 1. The high protein content of blueberry pomace, compared to the fresh fruit $(4,7 \mathrm{~g} / 100 \mathrm{~g}$, U.S Department of Agriculture, 2016) is related to the fact that pomace is constituted in a $19 \%$ by skins (Lee $\&$ Wrolstad, 2004), where $5-10 \%$ of its composition are structural proteins (Blaker \& Olmstead, 2015). The value of total carbohydrates is lower than the fresh fruit

Table 1. Proximate composition of blueberry pomace powder (BPP).

\begin{tabular}{cc}
\hline & BPP $(\mathrm{g} / 100 \mathrm{~g} \mathrm{dwb})$ \\
\hline Protein & $6.64 \pm 0.08$ \\
Lipids & $4.05 \pm 0.01$ \\
Ash & $2.06 \pm 0.01$ \\
Dietary fibre & $26.15 \pm 0.23$ \\
Carbohydrates & $60.94^{1}$ \\
\hline
\end{tabular}

${ }^{1}$ - Carbohydrates content obtained by difference.
(76.5 g/100 g dwb, U.S Department of Agriculture, 2016) because all of the non-structural carbohydrates remain in the juice.

Both blueberry and derived products present low lipids content. However, the blueberry pomace powder presented higher lipids content than the fresh fruit $(2.7 \mathrm{~g} / 100 \mathrm{~g} \mathrm{dwb}$, U.S Department of Agriculture, 2016). The difference is mainly attributed to pomace high content of seeds rich in fatty acids resulting in an increase of the amount of lipids.

The amount of dietary fibre is high compared to fresh fruit (15 g/100 g dwb U.S Department of Agriculture, 2016) due to the pomace composition, being rich in skins and seeds. The main component in dried pomace is dietary fibre from cell wall components, which are approximately 68\% (Struck et al., 2016). The seeds are also rich in dietary fibre, especially lignin and hemicellulose (Moldes et al., 2003). Moreover, these components are concentrated in the pomace, since it was dried. Because of the high content of dietary fibre, pomace powder may be a useful ingredient in the development of functional food. Functional properties of blueberry pomace powder are shown in Table 2 . The antioxidant capacity of blueberries has been highly correlated to their anthocyanin and total phenolic contents (Prior et al., 1998; Struck et al., 2016). Antioxidant capacity was calculated as the sum of ABTS extractable and hydrolysable fraction of the blueberry pomace powder. Results shown by the ABTS radical scavenging activity concluded that $69 \%$ of the antioxidant capacity was due to the hydrolysable fraction, related to antioxidant fibre compounds. Only $31 \%$ of the antioxidant capacity was from the extractable fraction. Different types of berry pomaces exhibit higher antioxidant capacity and total phenolic content than the fresh fruits as reported by Struck et al. (2016). This can be explained by the fact that antioxidants associated to wall compounds located in the skins and seeds remain in the pomace after juice production (White et al., 2011).

The sum of extractable and hydrolysable fractions antioxidant capacity was $339.09 \pm 2.69 \mu \mathrm{M} \mathrm{TE} / \mathrm{g} \mathrm{dwb}$, which is significantly higher when compared to other berry pomaces, such as strawberry (71.71 $\mu \mathrm{M} \mathrm{TE} / \mathrm{g} \mathrm{dwb})$, raspberry $(30.89 \mu \mathrm{M} \mathrm{TE} / \mathrm{g} \mathrm{dwb})$ and blackberry pomaces $(12.36 \mu \mathrm{M} \mathrm{TE} / \mathrm{g} \mathrm{dwb})$, as reported by Struck et al. (2016). This difference is explained by the aggressive extraction method used in this work for the hydrolysable phenolic fraction, which remained with the extraction solution for 20 hours. This procedure released the antioxidants

Table 2. Functional properties of blueberry pomace powder (BPP).

\begin{tabular}{lc}
\hline & BPP \\
\hline ABTS Extractable fraction $^{1}$ & $104.74 \pm 1.16$ \\
ABTS Hydrolysable fraction $^{1}$ & $234.35 \pm 2.43$ \\
Total antioxidant capacity $^{1,4}$ & $339.09 \pm 2.69$ \\
Extractable phenols $^{2}$ & $102.34 \pm 2.44$ \\
Hydrolysable phenols $^{2}$ & $182.80 \pm 3.76$ \\
Total phenols $^{2,4}$ & $285.14 \pm 4.48$ \\
Total anthocyanins $^{3}$ & $125.82 \pm 5.89$ \\
\hline
\end{tabular}

${ }^{1}$ - in $\mu \mathrm{M}$ TE/g dry weight basis (dwb); ${ }^{2}$ in mg gallic acid/gdwb; ${ }^{3}$ - in mg cyanidin-3glucoside/100g dwb; ${ }^{4}$-Total fraction refers to the sum of extractable and hydrolysable fraction. 
compounds from the cell wall. A higher number of hydrolysable polyphenols extracted may result in a higher antioxidant capacity. Blueberry powder antioxidant capacity was also higher than the result obtained by Reque et al. (2014) for blueberry flour $(41.93 \pm 0.36 \mu \mathrm{M} \mathrm{TE} / \mathrm{g} \mathrm{dwb})$. Difference may be attributed, neglecting the extraction method, to the processing conditions during drying (time, temperature and drying method) since bioactive compounds including phenols and anthocyanins are easily degraded (Skrede et al., 2000). Moreover, antioxidant capacity is mainly due to phenolic compounds. Apart from the skins' compounds with antioxidant capacity, seeds are also an important source of valuable compounds. Residues of berry seeds have shown to exhibit high levels of antioxidant capacity, being comparable to the level in herbs (Struck et al., 2016).

The fraction of hydrolysable polyphenol is significantly higher compared to the extractable fraction. The sum of extractable and hydrolysable polyphenolic fraction was used to calculate total phenolic content as done by Vitali et al. (2009) and suggested by Saura-Calixto et al. (2007). The TPC results showed that the content of soluble polyphenols was $102.34 \pm 2.44 \mathrm{mg}$ gallic $\mathrm{acid} / \mathrm{g} \mathrm{dwb}$. Phenols content concerning the hydrolysable fraction was $182.80 \pm 3.76 \mathrm{mg}$ gallic acid/g dwb; that is, $64 \%$ of the total phenols are in the hydrolysable fraction, bound to dietary fibre. The hydrolysable fraction along with the antioxidant capacity would be lost as the skins of berries are not part of the juice, demonstrating the high nutritional content and functional properties of the blueberry by-product and its potential use in functional foods. Contents of total phenols are higher than berry pomace data from Struck et al. (2016). Difference is mainly due to the fact that pomace has a moisture content of approximately $50 \%$ whereas blueberry pomace powder was dried and the compounds are highly concentrated. Besides, Folin-Ciocalteu assay may overestimate the content of polyphenols in cases in which there are other compounds with reducing groups present that can also transfer electrons but are not phenolics (Karadag et al., 2009).

Total anthocyanin content of the blueberry pomace dried powder was $125.82 \pm 5.89 \mathrm{mg}$ cyanidin-3-glucoside/100g dwb. Results are similar to the ones reported by Khanal et al. (2009) where the anthocyanin content was 102.3 to $175.7 \mathrm{mg} / 100 \mathrm{~g} \mathrm{dwb}$. Differences in anthocyanins content with blueberry flour reported by Reque et al. (2014) could be attributed to the juice mashing steps as anthocyanins are susceptible to degradative reactions during various processing unit operations (Khanal et al., 2009; Skrede et al., 2000). The drying conditions of the pomace could also affect the content of anthocyanins given their susceptibility to degradation when exposed to heat.

Anthocyanin content of blueberry pomace is generally higher than in fresh fruits (Lee et al. 2002; Reque et al., 2014; Struck et al., 2016). This is mainly related to the fact that anthocyanins exist almost in the skin (Lee \& Wrolstad, 2004). While disposal of blueberry waste is an important cost to the juice processing industry, it also represents a significant loss of a rich source of bioactive compounds with potential health benefits. Therefore, using this rich source as an ingredient is of utmost importance.

\subsection{Optimization of cookies' formulation}

The antioxidant capacity and total polyphenol content of cookies are shown in Table 3. The equation that represents the relationship between antioxidant capacity $\left(\mathrm{Y}_{1}\right)$ and total polyphenol content $\left(\mathrm{Y}_{2}\right)$ with fibre content $\left(\mathrm{X}_{1}\right)$, baking temperature $\left(\mathrm{X}_{2}\right)$ and dough thickness $\left(\mathrm{X}_{3}\right)$ are (Equation 2 and 3 ).

$$
\begin{aligned}
& Y_{1}=3422.5+27.898 X_{1}-40.990 X_{2}+ \\
& 235.78 X_{3}+0.11856 X_{2}{ }^{2}-176.70 X_{3}^{2} \\
& Y_{2}=-4432.9+27.900 X_{1}+51.771 X_{2}-44.224 X_{3}-0.1522 X_{2}^{2}
\end{aligned}
$$

\begin{tabular}{|c|c|c|c|c|c|}
\hline Formulation & $\mathrm{X}_{1}$ & $\mathrm{X}_{2}$ & $\mathrm{X}_{3}$ & Total polyphenol content ${ }^{1}$ & Antioxidant capacity $^{2}$ \\
\hline 1 & 9 & 160 & 0.5 & $205.46 \pm 2.30^{\mathrm{e}, \mathrm{f}}$ & $105.23 \pm 4.88^{\mathrm{g}, \mathrm{h}}$ \\
\hline 2 & 9 & 180 & 0.5 & $210.88 \pm 0.73^{\mathrm{f}, \mathrm{g}}$ & $107.97 \pm 1.41^{\mathrm{h}}$ \\
\hline 3 & 3 & 180 & 1 & $45.23 \pm 0.81^{\mathrm{a}}$ & $16.88 \pm 1.14^{\mathrm{a}}$ \\
\hline 4 & 6 & 180 & 0.75 & $145.96 \pm 0.06^{\mathrm{b}, \mathrm{c}}$ & $87.89 \pm 0.10^{e, f}$ \\
\hline 5 & 6 & 170 & 0.75 & $132.00 \pm 3.47^{\mathbf{b}}$ & $90.54 \pm 5.67^{f, g}$ \\
\hline 6 & 3 & 160 & 0.5 & $68.20 \pm 2.11^{\mathrm{a}}$ & $62.73 \pm 6.63^{c, d}$ \\
\hline 9 & 6 & 170 & 0.5 & $173.00 \pm 0.42^{\mathrm{d}, \mathrm{e}}$ & $74.39 \pm 8.57^{\mathrm{d}, \mathrm{e}}$ \\
\hline 10 & 3 & 160 & 1 & $51.84 \pm 0.28^{\mathrm{a}}$ & $34.95 \pm 4.10^{b}$ \\
\hline 11 & 3 & 170 & 0.75 & $65.60 \pm 0.13^{\mathrm{a}}$ & $13.24 \pm 3.67^{\mathrm{a}}$ \\
\hline 12 & 9 & 160 & 1 & $201.31 \pm 0.89^{e, f}$ & $104.55 \pm 1.70^{\mathrm{g}, \mathrm{h}}$ \\
\hline 13 & 9 & 170 & 0.75 & $232.32 \pm 1.28^{\mathrm{g}}$ & $117.22 \pm 1.78^{\mathrm{h}}$ \\
\hline
\end{tabular}

Table 3. Experimental matrix design for the three factors: $\mathrm{X}_{1}\left(\right.$ fibre content in percentage); $\mathrm{X}_{2}$ (baking temperature in Celsius degree) and $\mathrm{X}_{3}$ (dough thickness in centimeter) and results for total polyphenol content and antioxidant capacity of cookies.

For each parameter, values not shearing letters differ significantly ( $>0.05) .{ }^{1}-\mathrm{mg}$ gallic acid/g wwb; ${ }^{2}-\mu \mathrm{M} \mathrm{TE} / \mathrm{g}$ Wet weight basis (wwb). 
Table 4. Estimated regression coefficients of the fitted equations obtained for Antioxidant capacity and Total polyphenol content of cookies depending on fibre content (A), baking temperature (B) and dough thickness (C).

\begin{tabular}{|c|c|c|c|c|}
\hline \multirow{2}{*}{ Item } & \multicolumn{2}{|c|}{$\mathrm{p}$-value } & \multicolumn{2}{|c|}{ Coefficients } \\
\hline & Antioxidant capacity & Total polyphenol content & Antioxidant capacity & Total polyphenol content \\
\hline Constant & & & 3422.52 & -4369.40 \\
\hline A & 0.0000 & 0.0000 & 27.8984 & 24.9007 \\
\hline B & 0.0082 & 0.1884 & -40.9907 & 51.7717 \\
\hline $\mathrm{C}$ & 0.0042 & 0.0006 & 235.785 & -44.2242 \\
\hline AA & 0.0175 & 0.7031 & -1.29535 & $\mathrm{~ns}^{1}$ \\
\hline $\mathrm{AB}$ & 0.0535 & 0.7834 & $\mathrm{~ns}^{1}$ & $\mathrm{~ns}^{1}$ \\
\hline $\mathrm{AC}$ & 0.374 & 0.1848 & $\mathrm{~ns}^{1}$ & $n s^{1}$ \\
\hline $\mathrm{BB}$ & 0.0159 & 0.0066 & 0.118569 & -0.15227 \\
\hline $\mathrm{BC}$ & 0.9686 & 0.4916 & $\mathrm{~ns}^{1}$ & $\mathrm{~ns}^{1}$ \\
\hline $\mathrm{CC}$ & 0.0235 & 0.9912 & -176.705 & $\mathrm{~ns}^{1}$ \\
\hline $\mathrm{R} 2$ & & & 0.9138 & 0.9678 \\
\hline Standard error & & & 108.054 & 119.458 \\
\hline Lack-of-fit & 0.6260 & 0.6914 & & \\
\hline
\end{tabular}

${ }^{1}$ - Terms not significantly different from zero $(\mathrm{p}>0.05)$.

The estimated model for antioxidant capacity was adequate to describe the antioxidant capacity of cookies in a $91.83 \%$ of the variation of the response variable $\left(\mathrm{R}^{2}=0.9183\right)$ and the model had not significant lack-of-fit $(\mathrm{P}>0.05)$.

Results of ANOVA for the model, the regression coefficients and the coefficient of determination $\mathrm{R}^{2}$ are shown in Table 4.

For total polyphenol content the model was able to explain $96.78 \%$ of the response variable $\left(\mathrm{R}^{2}=0.9678\right)$ and the ANOVA showed that there was no significant lack of fit $(\mathrm{P}>0.05)$, showing that the selected model is adequate to describe the effect of the three independent variables on the response variables. For all of the terms in the model, a large regression coefficient and a small p-value indicate a more significant effect on the response variables (Wani et al., 2015).

In both models, the goodness of fit was evaluated by coefficient of determination $\mathrm{R}^{2}$, standard error and the lack-of-fit from the analysis of variance (ANOVA).

According to the models and as it can be seen from the response surface plots (Figure 1 and 2), antioxidant capacity and total polyphenol content are mainly influenced by fibre content, having a positive effect in the studied range (3-9\%). Fibre content is provided by the blueberry pomace powder added which exhibits high values of antioxidant capacity. These results agree with investigations in other antioxidant enriched cookies formulations. Mir et al. (2017) studied the effect of incorporating $3 \%, 6 \%$ and $9 \%$ apple pomace in gluten free crackers. They reported that the increased amount of apple pomace in the cookie formulation resulted in higher antioxidant properties, total dietary fibre and minerals in the final product.

For antioxidant capacity, according to the model, both linear and quadratic parameters of fibre, baking temperature and dough thickness were highly significant $(\mathrm{P}<0.001$ or $\mathrm{P}<0.05)$ with baking temperature and dough thickness having a negative effect on the antioxidant capacity (Figure 1). Zilic et al. (2016) found that the baking process increased the content of total phenolic compounds by affecting the solubility of bound forms of phenolic acids in anthocyanin-rich corn flour cookies. They also observed that the content of phenolic compounds in the cookies was significantly affected by baking temperature and baking time decreasing with the temperature and increasing with the time.

ANOVA shows that cross-products terms are not significantly different from zero $(\mathrm{P}>0.05)$ which indicates that interactions did not have any influence on the response variable. The correlation coefficient between antioxidant capacity and total polyphenols was 0.89 , suggesting that the strong antioxidant capacity exhibited by the cookies is explained by the fibre added with blueberry pomace as an ingredient.

Since the final goal of RSM was to optimize the cookies formulation (fibre, baking temperature and dough thickness), an optimization was conducted specifying the criteria of maximum antioxidant capacity and total polyphenol content. Optimum conditions for antioxidant capacity $(124.174 \mu \mathrm{M} \mathrm{TE} / \mathrm{g}$ wwb) were found to be $9 \%$ fibre, $160{ }^{\circ} \mathrm{C}$ baking temperature and $0.668 \mathrm{~cm}$ of dough thickness. The maximum total polyphenol content was achieved at $233.185 \pm 11.9460 \mathrm{mg}$ gallic acid/g wwb whereas the combination of factor levels maximizing were found to be $9 \%$ at fibre content, baking temperature $170{ }^{\circ} \mathrm{C}$ and $0.5 \mathrm{~cm}$ dough thickness.

According to results, the maximum antioxidant capacity and polyphenol content were obtained in cookie with $9 \%$ fibre, $180{ }^{\circ} \mathrm{C}$ baking temperature and $0.5 \mathrm{~cm}$ dough thickness and cookie with $9 \%$ of fibre, $170{ }^{\circ} \mathrm{C}$ baking temperature and $0.75 \mathrm{~cm}$ dough thickness, showing no significant differences between them. These two formulations of cookies can be labeled using a fibre claim. 
(a)

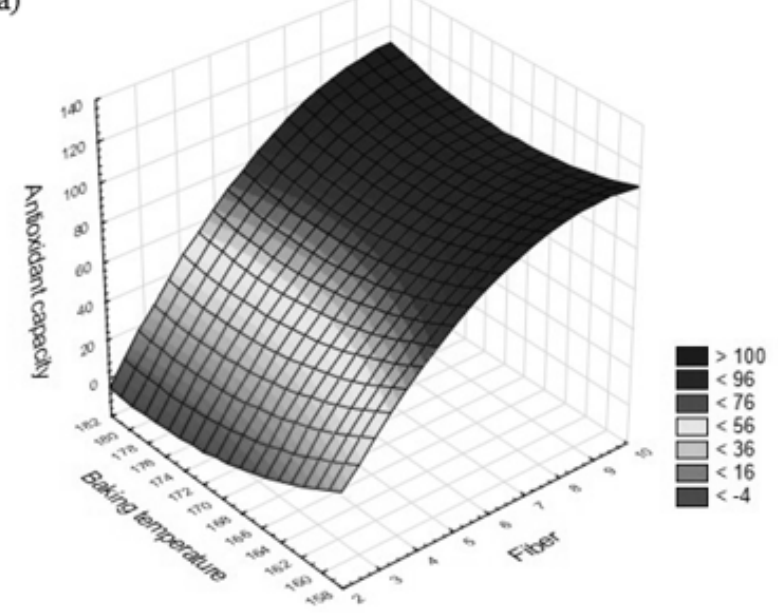

(b)

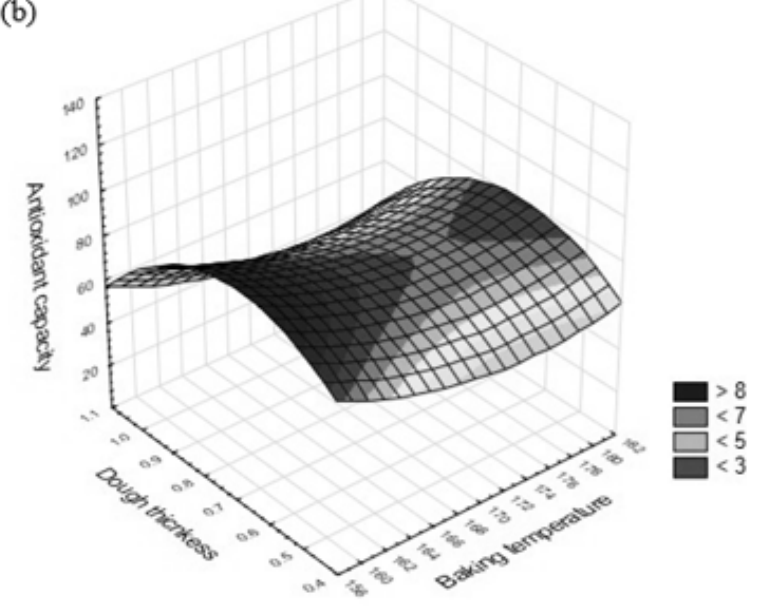

(c)

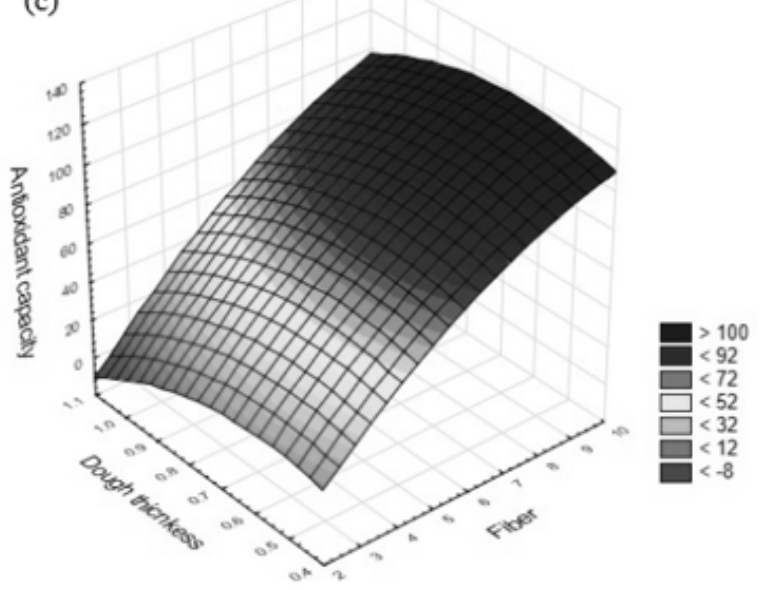

Figure 1. Effect of (a) Baking temperature and Fibre; (b) Dough thickness and Baking temperature; (c) Dough thickness and Fibre on the Antioxidant capacity.

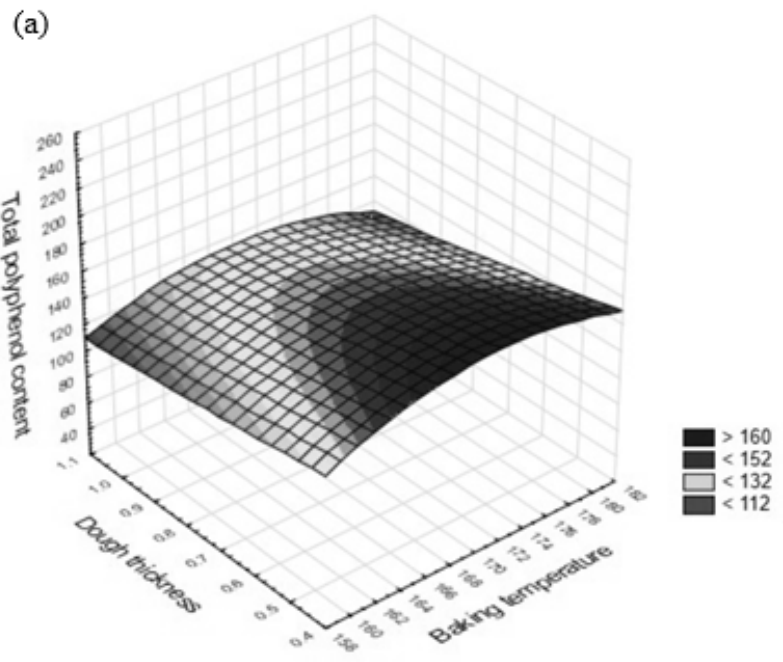

(b)
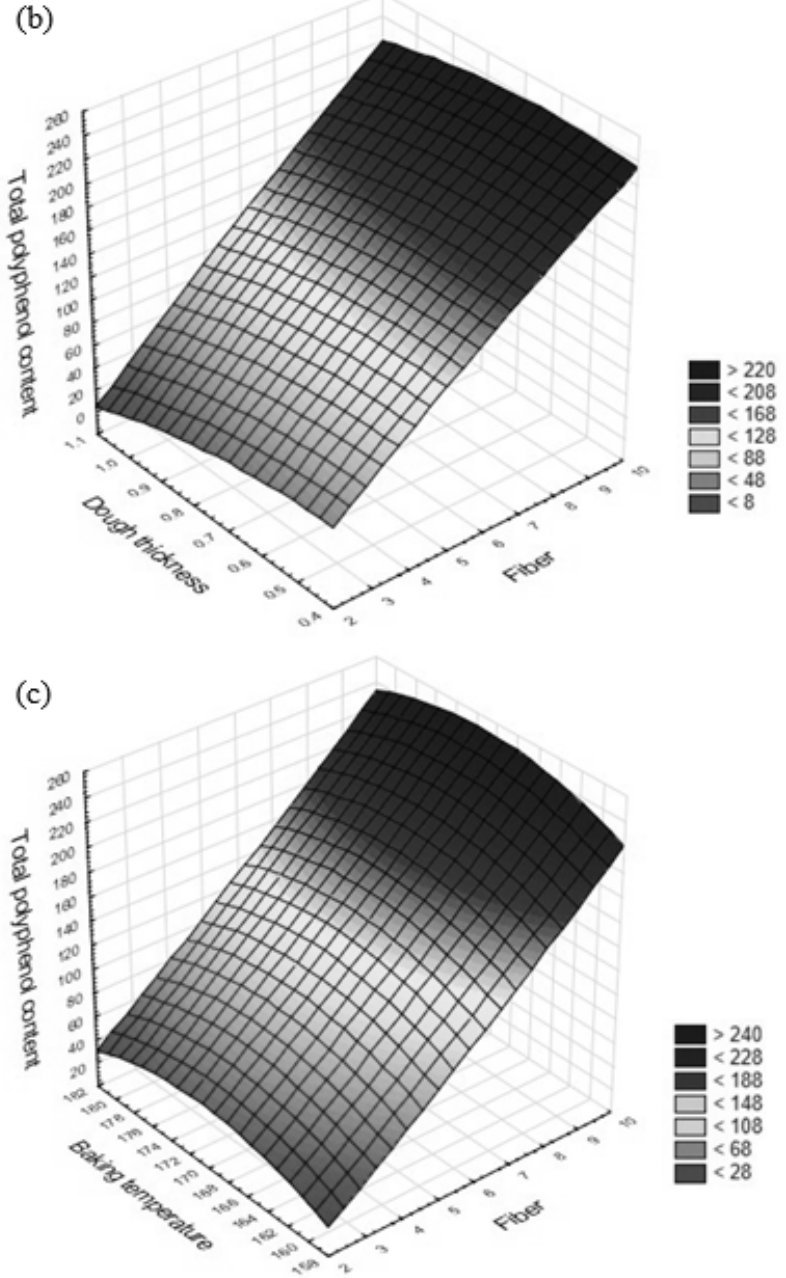

Figure 2. Effect of (a) Dough thickness and Baking temperature; (b) Dough thickness and Fibre; (c) Baking temperature and Fibre on Total polyphenol content. 


\section{Conclusion}

Blueberry pomace showed to be a source of fibre with an important antioxidant capacity, being highly correlated to polyphenol and anthocyanin contents. Antioxidant capacity was mainly due to the hydrolysable fraction, explained by the bioactive compounds bonded to the fibre. The hydrolysable fraction was also the majority fraction in the total polyphenol content, with a $64 \%$ of the phenolic compounds. Blueberry pomace may be a functional ingredient source of antioxidant dietary fibre.

The experimental design allowed optimizing cookie formulation in order to maximize functional properties and to obtain the maximum benefit of blueberry pomace. It was achieved at $9 \%$ fibre, $160{ }^{\circ} \mathrm{C}$ baking temperature, $0.67 \mathrm{~cm}$ dough thickness for antioxidant capacity and $9 \%$ fibre, $180{ }^{\circ} \mathrm{C}$ baking temperature, $0.50 \mathrm{~cm}$ dough thickness for total polyphenol content.

According to the actual habits for healthy food, blueberry pomace it's an interesting and successful approach to improve nutritional value of cookies due to its high antioxidant capacity.

The present work represents an innovative strategy for revaluation of the juice industry waste by developing a new ingredient that has a potential use in the field of functional food.

This waste management strategy not only avoids residues generation but uses both economic and environmental friendly technologies.

\section{References}

Association of Official Analytical Chemists - AOAC. (2012). Official Methods of Analysis of AOAC international. (19th ed.). Maryland: AOAC International.

Bilgili, N., Ibanoglu, S., \& Herken, E. N. (2007). Effect of dietary fibre addition on the selected nutritional properties of cookies. Journal of Food Engineering, 78(1), 86-89. http://dx.doi.org/10.1016/j. jfoodeng.2005.09.009.

Blaker, K. M., \& Olmstead, J. W. (2015). Cell wall composition of the skin and flesh tissue of crisp and standard texture southern highbush blueberry genotypes. Journal of Berry Research, 5(1), 9-15. http:// dx.doi.org/10.3233/JBR-140085.

Gacula, M. (1993). Design and analysis of sensory optimization. Trumbull: Food and Nutrition Press.

Gao, L., Wang, S., Oomah, B. D., \& Mazza, G. (2002). Wheat quality: Antioxidant activity of wheat millstreams. In P. Ng \& C. W. Wrigley, Wheat Quality Elucidation (pp. 219-233). St. Paul: AACC International.

Hartzfeld, P. W., Forkner, R., Hunter, M. D., \& Hagerman, A. E. (2002). Determination of hydrolyzable tannins (gallotannins and ellagitannins) after reaction with potassium iodate. Journal of Agricultural and Food Chemistry, 50(7), 1785-1790. http://dx.doi. org/10.1021/jf0111155. PMid:11902913.

Ignat, I., Volf, I., \& Popa, V. I. (2011). A critical review of methods for characterisation of polyphenolic compounds in fruits and vegetables. Food Chemistry, 126(4), 1821-1835. http://dx.doi.org/10.1016/j. foodchem.2010.12.026. PMid:25213963.

InfoStat. (2014). InfoStat Version 2014. Argentina: Universidad Nacional de Córdoba. Retrieved from http://www.infostat.com.ar

International Organization for Standardization - ISO. ISO 59842002. Animal feeding stuffs - Determination of crude ash. (2002). Geneva: ISO.
International Organization for Standardization - ISO. ISO-64921999. Animal feeding stuffs - Determination of fat content. (1999). Geneva: ISO.

Karadag, A., Ozcelik, B., \& Saner, S. (2009). Review of methods to determine antioxidant capacities. Food Analytical Methods, 2(1), 41-60. http://dx.doi.org/10.1007/s12161-008-9067-7.

Khanal, R. C., Howard, L. R., Brownmiller, C. R., \& Prior, R. L. (2009). Influence of extrusion processing on procyanidin composition and total anthocyanin contents of blueberry pomace. Journal of Food Science, 74(2), 52-58. http://dx.doi.org/10.1111/j.1750-3841.2009.01063.x. PMid:19323751.

Lee, J., Durst, R. W., \& Wrolstad, R. E. (2002). Impact of Juice Processing on Blueberry Anthocyanins and Polyphenolics: Comparison of Two Pretreatments. JFS: Food Chemistry and Toxicology, 67(5), 1660-1667. http://dx.doi.org/10.1111/j.1365-2621.2002.tb08701.x.

Lee, J., \& Wrolstad, R. E. (2004). Extraction of Anthocyanins and Polyphenolics from blueberry processing waste. JFS: Food Chemistry and Toxicology, 69(7), C564-C573. http://dx.doi. org/10.1111/j.1365-2621.2004.tb13651.x.

Mir, S. A., Don Bosco, S. J., Shah, M. A., Santhalakshmy, S., \& Mir, M. M. (2017). Effect of apple pomace on quality characteristics of brown rice based cracker. Journal of the Saudi Society of Agricultural Sciences, 16(1), 25-32. http://dx.doi.org/10.1016/j.jssas.2015.01.001.

Moldes, D., Gallego, P. P., Rodríguez Couto, S., \& Sanromán, A. (2003). Grape seeds: The best)lignocellulosic waste to produce laccase by solid state cultures of Trametes hirsuta. Biotechnology Letters, 25(6), 491-495. http://dx.doi.org/10.1023/A:1022660230653. PMid:12882277.

Palafox-Carlos, H., Ayala-Zavala, J. F., \& González-Aguilar, G. A. (2011). The Role of Dietary Fiber in the Bioaccessibility and Bioavailability of Fruit and Vegetable Antioxidants. Journal of Food Science, 76(1), 6-15. http://dx.doi.org/10.1111/j.1750-3841.2010.01957.x. PMid:21535705.

Prior, R. L., Cao, G., Martin, A., Sofic, E., Mcewen, J., Brien, C., \& Mainland, M. (1998). Antioxidant capacity as influenced by total phenolic and anthocyanin content, maturity, and variety of Vaccinium Species. Journal of Agricultural and Food Chemistry, 8561(98), 26862693. http://dx.doi.org/10.1021/jf980145d.

Re, R., Pellegrini, N., Proteggente, A., Pannala, A., Yang, M., \& RiceEvans, C. (1999). Antioxidant activity applying an improved ABTS radical cation decolorization assay. Free Radical Biology \& Medicine, 26(9-10), 1231-1237. http://dx.doi.org/10.1016/S0891-5849(98)003153. PMid:10381194.

Reque, P. M., Steffens, R. S., Silva, A. M., Jablonski, A., Flôres, S. H., Rios, A., \& Jong, E. V. (2014). Characterization of blueberry fruits (Vaccinium spp.) and derived products. Food Science and Technology, 34(4), 773-779. http://dx.doi.org/10.1590/1678-457X.6470.

Ross, C. F., Hoye, C. Jr, \& Fernandez-Plotka, V. C. (2011). Influence of Heating on the Polyphenolic Content and Antioxidant Activity of Grape Seed Flour. Journal of Food Science, 76(6), 884-890. http:// dx.doi.org/10.1111/j.1750-3841.2011.02280.x. PMid:22417486.

Šarić, B., Mišan, A., Mandić, A., Nedeljković, N., Pojić, M., Pestorić, M., $\&$ Đilas, S. (2016). Valorisation of raspberry and blueberry pomace through the formulation of value-added gluten-free cookies. Journal of Food Science and Technology, 53(2), 1140-1150. http://dx.doi. org/10.1007/s13197-015-2128-1. PMid:27162394.

Saura-Calixto, F. (1998). Antioxidant dietary fiber product: a new concept and a potential food ingredient. Journal of Agricultural and Food Chemistry, 46(10), 4303-4306. http://dx.doi.org/10.1021/jf9803841.

Saura-Calixto, F., Serrano, J., \& Goñi, I. (2007). Intake and bioaccessibility of total polyphenols in a whole diet. Food Chemistry, 101(2), 492501. http://dx.doi.org/10.1016/j.foodchem.2006.02.006. 
Saura-Calixto, F. (2011). Dietary fiber as a carrier of dietary antioxidants: an essential physiological function. Journal of Agricultural and Food Chemistry, 59(1), 43-49. http://dx.doi.org/10.1021/jf1036596. PMid:21142013.

Singleton, V. L., \& Rossi, J. A. Jr (1965). Colorimetry of Total Phenolics with Phosphomolybdic-Phosphotungstic Acid Reagents. American Journal of Enology and Viticulture, 16(3), 144-158.

Skrede, G., Wrolstad, R. E., \& Durst, R. W. (2000). Changes in Anthocyanins and Polyphenolics During Juice Processing of Highbush Blueberries (Vaccinium corymbosum L.). Journal of Food Science, 65(2), 357-364. http://dx.doi.org/10.1111/j.1365-2621.2000.tb16007.x.

Struck, S., Plaza, M., Turner, C., \& Rohm, H. (2016). Review Berry pomace - a review of processing and chemical analysis of its polyphenols. International Journal of Food Science \& Technology, 51(6), 1305-1318. http://dx.doi.org/10.1111/ijfs.13112.

Szajdek, A., \& Borowska, E. J. (2008). Bioactive compounds and health-promoting properties of berry fruits: A Review. Plant Foods for Human Nutrition, 63(4), 147-156. http://dx.doi.org/10.1007/ s11130-008-0097-5. PMid:18931913.

U.S Department of Agriculture - USDA. National Nutrient Database for Standard Reference. (2016). National nutrient Database. (p. 4-9). Washington: USDA.
Vitali, D., Dragojević, I. V., \& Šebečić, B. (2009). Effects of incorporation of integral raw materials and dietary fibre on the selected nutritional and functional properties of biscuits. Food Chemistry, 114(4), 14621469. http://dx.doi.org/10.1016/j.foodchem.2008.11.032.

Wani, S. M., Jan, N., Wani, T. A., Ahmad, M., Masoodi, F. A., \& Gani, A. (2015). Optimization of antioxidant activity and total polyphenols of dried apricot fruit extracts (Prunus armeniaca L.) using response surface methodology. Journal of the Saudi Society of Agricultural Sciences, 16(2), 119-126. http://dx.doi.org/10.1016/j.jssas.2015.03.006.

White, B. L., Howard, L. R., \& Prior, R. L. (2011). Impact of different stages of juice processing on the anthocyanin, flavonol, and procyanidin contents of cranberries. Journal of Agricultural and Food Chemistry, 59(9), 4692-4698. http://dx.doi.org/10.1021/jf200149a. PMid:21438531.

Wrolstad, R. E. (2001). Characterization and Measurement of Anthocyanins by UV-Visible Spectroscopy. In R. E. Wrolstad. Current Protocols in Food Analytical Chemistry. Hoboken: John Wiley and Sons, Inc.

Zilic, S., Kocadagli, T., Vancetovic, J., \& Gökmen, V. (2016). Effects of baking conditions and dough formulations on phenolic compound stability, antioxidant capacity and color of cookies made from anthocyanin-rich corn flour. Lebensmittel-Wissenschaft + Technologie, 65, 597-603. http://dx.doi.org/10.1016/j.lwt.2015.08.057. 